\section{Four Reference Quality Genome Assemblies of Pyrenophora teres f. maculata: A Resource for Studying the Barley Spot Form Net Blotch Interaction}

\author{
Nathan A. Wyatt and Timothy L. Friesen ${ }^{\dagger}$ \\ USDA-ARS Edward T. Schafer Agricultural Research Center, Cereal Crops Research Unit, Fargo, ND, \\ U.S.A.
}

\begin{abstract}
Pyrenophora teres is the causal agent of net blotch, the most devastating foliar disease of barley. In nature, net blotch is seen in two forms, net form net blotch, caused by $P$. teres $\mathrm{f}$. teres, and spot form net blotch, caused by $P$. teres f. maculata. To date, $11 P$. teres f. teres genomes have been sequenced and deposited in publicly available repositories, but only one $P$. teres f. maculata genome has been publicly deposited. Here, we present four additional reference-quality full-genome sequences of $P$. teres $\mathrm{f}$. maculata isolates with good geographical and phenotypic diversity, with accompanying RNA sequencing-based genome annotations. These additional $P$. teres f. maculata genomes will aid in the understanding of the genomic complexities of this important barley pathogen.
\end{abstract}

\section{Genome Announcement}

Net blotch is the most economically important foliar disease of barley, as it is present across all barley-growing regions and typical yield losses range from 10 to $40 \%$, with potential for total crop loss given environmental conditions favorable to the pathogen. Net blotch is caused by the necrotrophic fungus Pyrenophora teres that exists in two forms, $P$. teres $\mathrm{f}$. teres, causal agent of net form net blotch and $P$. teres $\mathrm{f}$. maculata, causal agent of spot form net blotch (Smedegård-Petersen 1971). The two forms can be distinguished by the lesions formed on infected barley leaf tissue, with $P$. teres $f$. teres forming necrotic striated lesions with a distinct net-like pattern and $P$. teres $\mathrm{f}$. maculata forming oval necrotic lesions with a chlorotic halo (Shipton et al. 1973; Smedegård-Petersen 1971). Previous work has argued that the two forms of $P$. teres could be classified as separate species, based on their genetic isolation and the rarity of hybridization of the two forms in nature, despite their presence in the same field and often infecting the same leaf (Clare et a. 2020; Ellwood et al. 2012; Jalli 2011; Rau et al. 2007; Syme et al. 2018). Though the two forms of $P$. teres are often present in the same field, one form is often dominant within a geographical region, due to the susceptibility of the predominant cultivars planted, for which the two forms vary in virulence (Clare et al. 2020).

Recent genomic resources for $P$. teres $\mathrm{f}$. teres have been released and provided critical information about the genome of this important plant pathogen. The first $P$. teres $\mathrm{f}$. teres genome sequenced was the Canadian isolate $0-1$, which was sequenced using Illumina sequencing (Ellwood et al. 2010), and later, the 0-1 genome was resequenced using Pacific

\footnotetext{
${ }^{\dagger}$ Corresponding author: T. L. Friesen: timothy.friesen@usda.gov
}

The author(s) declare no conflict of interest.

Accepted for publication 9 October 2020.

\section{Keywords}

fungus-plant interactions, fungal genomics, net blotch, PacBio, Pyrenophora teres, transcriptomics 
Biosciences long-read sequencing to obtain a near chromosome level reference genome (Wyatt et al. 2018). Due to the decreased costs in sequencing technologies, it is now feasible to have multiple representative reference-quality genomes for a single species (Goodwin et al. 2016; Thomma et al. 2016). Four additional $P$. teres f. teres isolates were sequenced and assembled to near chromosome resolution and were used in a comparative analysis with the reference isolate 0-1 (Wyatt et al. 2020). The comparative analysis of the five genomes revealed important genomic architecture relating to known virulence loci in $P$. teres $\mathrm{f}$. teres and established common trends within the $P$. teres f. teres genomes (Wyatt et al. 2020). The first and only $P$. teres $\mathrm{f}$. maculata genome sequence released was the Australian isolate SG1. SG1 was sequenced using long-read technology and was optically mapped to produce near chromosome level scaffolds (Syme et al. 2018). A comparative analysis was performed between the $P$. teres f. maculata SG1 genome and the $P$. teres f. teres genomes $\mathrm{W} 1-1$ and $0-1$, revealing differences between the genomes of the two forms primarily relating to expansions of repeat elements in $P$. teres $\mathrm{f}$. teres that were absent from $P$. teres f. maculata (Syme et al. 2018).

To date there are 11 total genome sequences for $P$. teres $\mathrm{f}$. teres publicly available but only one $P$. teres $\mathrm{f}$. maculata genome. The lack of available $P$. teres $\mathrm{f}$. maculata genomes presents an obstacle to comparative analysis both within and between the two forms of $P$. teres. In order to produce additional $P$. teres $f$. maculata genomic resources, we used Pacific Biosciences long-read sequencing to sequence four $P$. teres $f$. maculata isolates from diverse geographical locations, FGOB10Ptm-1 (North Dakota, U.S.A.), P-A14 (Montana, U.S.A.), and Den2.6 (Denmark), and NZKF2 (New Zealand), to complement the already available Australian isolate SG1. Additionally, we performed RNA sequencing of in vitro culture and four in planta infection timepoints for isolate FGOB10Ptm-1, to aid in annotating these $P$. teres f. maculata genomes. Isolates FGOB10Ptm-1, P-A14, Den2.6, and NZKF2 were chosen based on their geographical diversity and their previous use in disease evaluations (Carlsen et al. 2017; Neupane et al. 2015; Tamang et al. 2015, 2019).

High-molecular weight DNA was extracted from isolates FGOB10Ptm-1, P-A14, Den2.6, and NZKF2, following a modified CTAB method as outlined by Wyatt et al. (2020). For isolate FGOB10Ptm-1, high-molecular weight DNA was then shipped on dry ice to the Mayo Clinic Genome Analysis Core facility in Rochester, Minnesota, for sequencing on a Pacific Biosciences RSII, using nine single-molecule real-time cells. For isolates P-A14, Den2.6, and NZKF2, high-molecular weight DNA was shipped on dry ice to the Genomics and Bioinformatics Research Unit at the United States Department of Agriculture Agricultural Research Service (USDA-ARS) station in Stoneville, Mississippi. Each isolate was sequenced using a $20-k b$ size-selected library on a Pacific Biosciences RSII or Sequel to $>200 \times$ coverage. Genomes were assembled as described by Wyatt et al. (2020); briefly, Canu v1.8 (Koren et al. 2017) was used with FASTQ file inputs for correction, trimming, and assembly. Genome assemblies were polished using 20x coverage lon Torrent sequencing, using the genome polishing program Pilon (Walker et al. 2014). Briefly, lon Torrent sequencing was performed following a two restriction enzyme digest of genomic DNA with the restriction enzymes Hhal and ApeKI and Ion Torrent adapter ligation (Leboldus et al. 2015). Genome assemblies for isolates FGOB10Ptm-1, Den2.6, and NZKF2 resulted in less than complete chromosome level assemblies and were therefore aligned to the genome assembly of isolate P-A14 for scaffolding and gap estimation, using the program RagTag (Alonge et al. 2019).

RNA sequencing was performed as described by Wyatt et al. (2018) with samples taken from pure culture and in planta timepoints of 48,72h, 96, and $120 \mathrm{~h}$ postinoculation. Pure culture consisted of $P$. teres $\mathrm{f}$. maculata spores inoculated in Friese medium and allowed to grow in the dark for $72 \mathrm{~h}$. The highly susceptible Pinnacle barley was sown into a 96-conetainer rack and was grown under greenhouse conditions for approximately 2 weeks. Pinnacle barley was inoculated with spores from isolate FGOB10Ptm-1 at a concentration of 2,000 spores $/ \mathrm{ml}$ and were placed into a lighted mist chamber for $24 \mathrm{~h}$, with $100 \%$ relative humidity. After $24 \mathrm{~h}$, inoculated plant material was moved to a growth chamber with a temperature of $21^{\circ} \mathrm{C}$ and a 12-h photoperiod. Inoculated leaf tissue was collected at the appropriate timepoint and was immediately flash-frozen in liquid nitrogen. Total mRNA from each sample was extracted using the mRNA Direct kit (Thermo-Fisher Scientific), following manufacturer protocol. RNA sequencing library preparation was done with the llumina Truseq v.3 kit, following the manufacturer protocol. RNA sequencing was performed on an Illumina 
Table 1. Genome summary statistics

\begin{tabular}{|c|c|c|c|c|}
\hline Genome statistic & P-A14 & NZKF2 & Den2.6 & FGOB10Ptm-1 \\
\hline Total genome size $(\mathrm{Mb})$ & 42.0 & 42.6 & 42.7 & 38.2 \\
\hline Contigs & 12 & 14 & 13 & 46 \\
\hline Scaffolds & 12 & 12 & 12 & 12 \\
\hline N50 scaffolds (Mb) ${ }^{a}$ & 3.9 & 3.8 & 4.1 & 3.4 \\
\hline $\mathrm{L} 50^{\mathrm{b}}$ & 5 & 5 & 5 & 5 \\
\hline Genes & 9,219 & 9,863 & 9,799 & 9,509 \\
\hline BUSCO score $(\%)^{c}$ & 96.3 & 98.2 & 98.5 & 98.8 \\
\hline Proteins with Pfam domain $(\%)^{d}$ & $60 \%$ & $62 \%$ & $61 \%$ & $60 \%$ \\
\hline Predicted secreted proteins ${ }^{\mathrm{e}}$ & 1,004 & 695 & 699 & 1,000 \\
\hline Predicted effectors ${ }^{f}$ & 258 & 180 & 187 & 257 \\
\hline
\end{tabular}

a N50 is the largest length L, such that $50 \%$ of all nucleotides are contained in scaffolds of size at least L (Bradnam et al. 2013; Earl et al. 2011; Lander et al. 2001).

b $L 50$ is the number $\mathrm{N}$ of sequences that comprise the N50 statistic.

c BUSCO scores are calculated with BUSCO v4, using the Ascomycota dataset (Simão et al. 2015).

d Proteins with Pfam domains were identified using the Funannotate accessory scripts (Palmer and Stajich 2017).

e Secreted proteins were predicted with SignalP 5.0 (Almagro Armenteros et al. 2019).

${ }^{\dagger}$ Effector proteins were predicted with EffectorP 2.0 (Sperschneider et al. 2018).

NextSeq at the USDA-ARS Small Grains Genotyping Center (Fargo, North Dakota) to produce 150 -bp single-end reads.

Gene models for each genome were generated in a similar manner to that of Wyatt et al. (2018), using the Maker2 genome annotation software (Holt and Yandell 2011). Briefly, amino acid sequences from the closely related species Pyrenophora tritici-repentis, $P$. teres f. teres, and the $P$. teres f. maculata isolate SG1 were input into the Maker2 software in conjunction with both de novo assembled and alignment-based transcripts from RNA sequencing data. Transcripts were de novo assembled using the program Trinity (Haas et al. 2013) and were aligned to the genomes of each isolate using HISAT2 (Kim et al. 2019), for subsequent transcript assembly with Stringtie (Pertea et al. 2016). Gene models were predicted from these inputs with a maximum intron length set to $3,000 \mathrm{bp}$ and were used as a training set for the ab initio genome annotation software SNAP (Johnson et al. 2008). This process was iteratively done twice more to produce final gene models. Gene models were then subject to Funannotate functions to provide functional annotations (Palmer and Stajich 2017). Secreted proteins were predicted with SignalP 5.0 (Almagro Armenteros et al. 2019) and effectors were predicted with EffectorP 2.0 (Sperschneider et al. 2018). Genome completeness was estimated using the program BUSCO with the Ascomycota data set (Simão et al. 2015).

The genome assembly of isolate P-A14 produced 12 total contigs representing the 12 chromosomes present in P. teres f. maculate, while the genome assemblies of Den2.6 and NZKF2 produced 13 and 14 total contigs, respectively, that were then aligned to the P-A14 genome and scaffolded into 12 chromosomes each (Table 1). Isolate FGOB10Ptm-1 assembly resulted in 46 contigs and was scaffolded into chromosome-based synteny with the P-A14 genome and was subsequently compared with the previously published FGOB10Ptm$1 \times$ SG1 genetic map (Table 1). Genome size of the four $P$. teres $f$. maculata genomes ranged from 38.2 to $42.7 \mathrm{Mb}$ (Table 1). Genome completeness was estimated for each genome, using the single copy orthologs from the BUSCO Ascomycota dataset with the four $P$. teres $\mathrm{f}$. maculata genomes scoring between 96.3 to $98.8 \%$ complete (Table 1).

Genome annotation of the four $P$. teres $f$. maculata genomes produced RNA sequencing guided gene models. Total gene models ranged from 9,219 to 9,863 with between 60 and $62 \%$ containing predicted Pfam domains (Table 1). Secreted proteins are particularly interesting for plant pathogens, as they are often involved in the pathogen-host interaction and 695 to 1,004 secreted proteins were identified in the four $P$. teres f. maculata genomes, with 180 to 258 predicted by EffectorP 2.0 to be effectors (Table 1 ).

These newly generated genomes and annotations of $P$. teres $f$. maculata isolates will provide necessary genomic resources for the investigation of spot form net blotch of barley. The genomic resources generated will aid in effector identification and characterization in $P$. teres f. maculata and will also increase the speed of resistance and susceptibility gene identification in barley. Additionally, these new genomic resources will be useful for comparative studies both within $P$. teres f. maculata and between $P$. teres $f$. maculata and $P$. teres 


\section{Literature Cited}

Almagro Armenteros, J. J., Tsirigos, K. D., Sønderby, C. K., Petersen, T. N., Winther, O., Brunak, S., von Heijne, G., and Nielsen, H. 2019. SignalP 5.0 improves signal peptide predictions using deep neural networks. Nat. Biotechnol. 37:420-423.

Alonge, M., Soyk, S., Ramakrishnan, S., Wang, X., Goodwin, S., Sedlazeck, F. J., Lippman, Z. B., and Schatz, M. C. 2019. RaGOO: Fast and accurate referenceguided scaffolding of draft genomes. Genome Biol. 20:224.

Bradnam, K. R., Fass, J. N., Alexandrov, A., Baranay, P., Bechner, M., Birol, I., Boisvert, S., Chapman, J. A., Chapuis, G., Chikhi, R., Chitsaz, H., Chou, W. C., Corbeil, J., Del Fabbro, C., Docking, T. R., Durbin, R., Earl, D., Emrich, S., Fedotov, P., Fonseca, N. A., Ganapathy, G., Gibbs, R. A., Gnerre, S., Godzaridis, E., Goldstein, S., Haimel, M., Hall, G., Haussler, D., Hiatt, J. B., Ho, I. Y., Howard, J., Hunt, M., Jackman, S. D., Jaffe, D. B., Jarvis, E. D., Jiang, H., Kazakov, S., Kersey, P. J., Kitzman, J. O., Knight, J. R., Koren, S., Lam, T. W., Lavenier, D., Laviolette, F., Li, Y., Li, Z., Liu, B., Liu, Y., Luo, R., Maccallum, I., Macmanes, M. D., Maillet, N., Melnikov, S., Naquin, D., Ning, Z., Otto, T. D., Paten, B., Paulo, O. S., Phillippy, A. M., Pina-Martins, F., Place, M., Przybylski, D., Qin, X., Qu, C., Ribeiro, F. J., Richards, S., Rokhsar, D. S., Ruby, J. G., Scalabrin, S., Schatz, M. C., Schwartz, D. C., Sergushichev, A., Sharpe, T., Shaw, T. I., Shendure, J., Shi, Y., Simpson, J. T., Song, H., Tsarev, F., Vezzi, F., Vicedomini, R., Vieira, B. M., Wang, J., Worley, K. C., Yin, S., Yiu, S. M., Yuan, J., Zhang, G., Zhang, H., Zhou, S., and Korf, I. F. 2013. Assemblathon 2: Evaluating de novo methods of genome assembly in three vertebrate species. Gigascience 2:10.

Carlsen, S. A., Neupane, A., Wyatt, N. A., Richards, J. K., Faris, J. D., Xu, S. S., Brueggeman, R. S., and Friesen, T. L. 2017. Characterizing the Pyrenophora teres f. maculata-barley interaction using pathogen genetics. G3 (Bethesda) 7: 2615-2626.

Clare, S. J., Wyatt, N. A., Brueggeman, R. S., and Friesen, T. L. 2020. Research advances in the Pyrenophora teres-barley interaction. Mol. Plant Pathol. 21: 272-288.

Earl, D., Bradnam, K., St John, J., Darling, A., Lin, D., Fass, J., Yu, H. O. K., Buffalo, V., Zerbino, D. R., Diekhans, M., Nguyen, N., Ariyaratne, P. N., Sung, W. K., Ning, Z., Haimel, M., Simpson, J. T., Fonseca, N. A., Birol, I., Docking, T. R., Ho, I. Y., Rokhsar, D. S., Chikhi, R., Lavenier, D., Chapuis, G., Naquin, D., Maillet, N., Schatz, M. C., Kelley, D. R., Phillippy, A. M., Koren, S., Yang, S. P., Wu, W., Chou, W. C., Srivastava, A., Shaw, T. I., Ruby, J. G., Skewes-Cox, P., Betegon, M., Dimon, M. T., Solovyev, V., Seledtsov, I., Kosarev, P., Vorobyev, D., RamirezGonzalez, R., Leggett, R., MacLean, D., Xia, F., Luo, R., Li, Z., Xie, Y., Liu, B., Gnerre, S., MacCallum, I., Przybylski, D., Ribeiro, F. J., Yin, S., Sharpe, T., Hall, G., Kersey, P. J., Durbin, R., Jackman, S. D., Chapman, J. A., Huang, X., DeRisi, J. L., Caccamo, M., Li, Y., Jaffe, D. B., Green, R. E., Haussler, D., Korf, I., and Paten, B. 2011. Assemblathon 1: A competitive assessment of de novo short read assembly methods. Genome Res. 21:2224-2241.

Ellwood, S. R., Liu, Z., Syme, R. A., Lai, Z., Hane, J. K., Keiper, F., Moffat, C. S., Oliver, R. P., and Friesen, T. L. 2010. A first genome assembly of the barley fungal pathogen Pyrenophora teres f. teres. Genome Biol. 11:R109.

Ellwood, S. R., Syme, R. A., Moffat, C. S., and Oliver, R. P. 2012. Evolution of three Pyrenophora cereal pathogens: Recent divergence, speciation and evolution of non-coding DNA. Fungal Genet. Biol. 49:825-829.

Goodwin, S., McPherson, J. D., and McCombie, W. R. 2016. Coming of age: Ten years of next-generation sequencing technologies. Nat. Rev. Genet. 17:333-351.

Haas, B. J., Papanicolaou, A., Yassour, M., Grabherr, M., Blood, P. D., Bowden, J., Couger, M. B., Eccles, D., Li, B., Lieber, M., MacManes, M. D., Ott, M., Orvis, J., Pochet, N., Strozzi, F., Weeks, N., Westerman, R., William, T., Dewey, C. N., Henschel, R., LeDuc, R. D., Friedman, N., and Regev, A. 2013. De novo transcript sequence reconstruction from RNA-seq using the Trinity platform for reference generation and analysis. Nat. Protoc. 8:1494-1512.

Holt, C., and Yandell, M. 2011. MAKER2: An annotation pipeline and genomedatabase management tool for second-generation genome projects. BMC Bioinformatics 12:491.

Jalli, M. 2011. Sexual reproduction and soil tillage effects on virulence of Pyrenophora teres in Finland. Ann. Appl. Biol. 158:95-105.
Johnson, A. D., Handsaker, R. E., Pulit, S. L., Nizzari, M. M., O'Donnell, C. J., and de Bakker, P. I. 2008. SNAP: A web-based tool for identification and annotation of proxy SNPs using HapMap. Bioinformatics 24:2938-2939.

Kim, D., Paggi, J. M., Park, C., Bennett, C., and Salzberg, S. L. 2019. Graph-based genome alignment and genotyping with HISAT2 and HISAT-genotype. Nat. Biotechnol. 37:907-915.

Koren, S., Walenz, B. P., Berlin, K., Miller, J. R., Bergman, N. H., and Phillippy, A. M. 2017. Canu: Scalable and accurate long-read assembly via adaptive $k$-mer weighting and repeat separation. Genome Res. 27:722-736.

Lander, E. S., Linton, L. M., Birren, B., Nusbaum, C., Zody, M. C., Baldwin, J., Devon, K., Dewar, K., Doyle, M., FitzHugh, W., Funke, R., Gage, D., Harris, K., Heaford, A., Howland, J., Kann, L., Lehoczky, J., LeVine, R., McEwan, P., McKernan, K., Meldrim, J., Mesirov, J. P., Miranda, C., Morris, W., Naylor, J., Raymond, C., Rosetti, M., Santos, R., Sheridan, A., Sougnez, C., Stange-Thomann, Y., Stojanovic, N., Subramanian, A., Wyman, D., Rogers, J., Sulston, J., Ainscough, R., Beck, S., Bentley, D., Burton, J., Clee, C., Carter, N., Coulson, A., Deadman, R., Deloukas, P., Dunham, A., Dunham, I., Durbin, R., French, L., Grafham, D., Gregory, S., Hubbard, T., Humphray, S., Hunt, A., Jones, M., Lloyd, C., McMurray, A., Matthews, L., Mercer, S., Milne, S., Mullikin, J. C., Mungall, A., Plumb, R., Ross, M., Shownkeen, R., Sims, S., Waterston, R. H., Wilson, R. K., Hillier, L. W., McPherson, J. D., Marra, M. A., Mardis, E. R., Fulton, L. A., Chinwalla, A. T., Pepin, K. H., Gish, W. R., Chissoe, S. L., Wendl, M. C. Delehaunty, K. D., Miner, T. L., Delehaunty, A., Kramer, J. B., Cook, L. L., Fulton, R. S., Johnson, D. L., Minx, P. J., Clifton, S. W., Hawkins, T., Branscomb, E., Predki, P., Richardson, P., Wenning, S., Slezak, T., Doggett, N., Cheng, J. F., Olsen, A., Lucas, S., Elkin, C., Uberbacher, E., Frazier, M., Gibbs, R. A., Muzny, D. M., Scherer, S. E., Bouck, J. B., Sodergren, E. J., Worley, K. C., Rives, C. M., Gorrell, J. H., Metzker, M. L., Naylor, S. L., Kucherlapati, R. S., Nelson, D. L., Weinstock, G. M., Sakaki, Y., Fujiyama, A., Hattori, M., Yada, T., Toyoda, A., Itoh, T., Kawagoe, C., Watanabe, H., Totoki, Y., Taylor, T., Weissenbach, J., Heilig, R., Saurin, W., Artiguenave, F., Brottier, P., Bruls, T., Pelletier, E., Robert, C., Wincker, P., Smith, D. R., Doucette-Stamm, L., Rubenfield, M., Weinstock, K., Lee, H. M., Dubois, J., Rosenthal, A., Platzer, M., Nyakatura, G., Taudien, S., Rump, A., Yang, H., Yu, J., Wang, J., Huang, G., Gu, J., Hood, L., Rowen, L., Madan, A., Qin, S., Davis, R. W., Federspiel, N. A., Abola, A. P., Proctor, M. J., Myers, R. M., Schmutz, J., Dickson, M., Grimwood, J., Cox, D. R., Olson, M. V., Kaul, R., Raymond, C., Shimizu, N., Kawasaki, K., Minoshima, S., Evans, G. A., Athanasiou, M., Schultz, R., Roe, B. A., Chen, F., Pan, H., Ramser, J., Lehrach, H., Reinhardt, R., McCombie, W. R., de la Bastide, M., Dedhia, N., Blöcker, H., Hornischer, K., Nordsiek, G., Agarwala, R., Aravind, L., Bailey, J. A., Bateman, A., Batzoglou, S., Birney, E., Bork, P., Brown, D. G., Burge, C. B., Cerutti, L., Chen, H. C., Church, D., Clamp, M., Copley, R. R., Doerks, T., Eddy, S. R., Eichler, E. E., Furey, T. S., Galagan, J., Gilbert, J. G., Harmon, C., Hayashizaki, Y., Haussler, D., Hermjakob, H., Hokamp, K., Jang, W., Johnson, L. S., Jones, T. A., Kasif, S., Kaspryzk, A., Kennedy, S., Kent, W. J., Kitts, P., Koonin, E. V., Korf, I., Kulp, D., Lancet, D., Lowe, T. M., McLysaght, A., Mikkelsen, T., Moran, J. V., Mulder, N., Pollara, V. J., Ponting, C. P., Schuler, G., Schultz, J., Slater, G., Smit, A. F., Stupka, E., Szustakowki, J., Thierry-Mieg, D., Thierry-Mieg, J., Wagner, L., Wallis, J., Wheeler, R., Williams, A., Wolf, Y. I., Wolfe, K. H., Yang, S. P., Yeh, R. F., Collins, F., Guyer, M. S., Peterson, J., Felsenfeld, A., Wetterstrand, K. A., Patrinos, A., Morgan, M. J., de Jong, P., Catanese, J. J., Osoegawa, K., Shizuya, H., Choi, S., Chen, Y. J., and Szustakowki, J. 2001. Initial sequencing and analysis of the human genome. Nature 409:860-921.

Leboldus, J. M., Kinzer, K., Richards, J., Ya, Z., Yan, C., Friesen, T. L., and Brueggeman, R. 2015. Genotype-by-sequencing of the plant-pathogenic fungi Pyrenophora teres and Sphaerulina musiva utilizing lon Torrent sequence technology. Mol. Plant Pathol. 16:623-632.

Neupane, A., Tamang, P., Brueggeman, R. S. and Friesen, T. L. 2015. Evaluation of a barley core collection for spot form net blotch reaction reveals distinct genotypespecific pathogen virulence and host susceptibility. Phytopathology 105:509-517.

Palmer, J. and Stajich, J. E. 2017. Funannotate: Eukaryotic genome annotation pipeline. Published online. https://github.com/nextgenusfs/funannotate 
Pertea, M., Kim, D., Pertea, G. M., Leek, J. T., and Salzberg, S. L. 2016. Transcriptlevel expression analysis of RNA-seq experiments with HISAT, StringTie and Ballgown. Nat. Protoc. 11:1650-1667.

Rau, D., Attene, G., Brown, A. H., Nanni, L., Maier, F. J., Balmas, V., Saba, E., Schäfer, W., and Papa, R. 2007. Phylogeny and evolution of mating-type genes from Pyrenophora teres, the causal agent of barley "net blotch" disease. Curr. Genet. 51:377-392.

Shipton, W. A., Khan, T. N., and Boyd, W. J. R. 1973. Net blotch of barley. Rev. Plant Pathol. 52:269-290.

Simão, F. A., Waterhouse, R. M., Ioannidis, P., Kriventseva, E. V., and Zdobnov, E. M. 2015. BUSCO: Assessing genome assembly and annotation completeness with single-copy orthologs. Bioinformatics 31:3210-3212.

Smedegård-Petersen, V. 1971. Pyrenophora teres f. maculata f. nov. and Pyrenophora teres f. teres on barley in Denmark. Kgl. Vet. Landbohojsk. Arsskr. 124-144.

Sperschneider, J., Dodds, P. N., Gardiner, D. M., Singh, K. B., and Taylor, J. M. 2018. Improved prediction of fungal effector proteins from secretomes with EffectorP 2.0. Mol. Plant Pathol. 19:2094-2110.

Syme, R. A., Martin, A., Wyatt, N. A., Lawrence, J. A., Muria-Gonzalez, M. J., Friesen, T. L., and Ellwood, S. R. 2018. Transposable element genomic fissuring in Pyrenophora teres is associated with genome expansion and dynamics of host-pathogen genetic interactions. Front. Genet. 9:130.
Tamang, P., Neupane, A., Mamidi, S., Friesen, T. L. and Brueggeman, R. S. 2015. Association mapping of seedling resistance to spot form net blotch in a worldwide collection of barley. Phytopathology 105:500-508.

Tamang, P., Richards, J. K., Alhashal, A., Poudel, R. S., Horsley, R. D., Friesen, T. L. and Brueggeman, R. S. 2019. Mapping of barley susceptibility/resistance QTL against spot form net blotch caused by Pyrenophora teres f. maculata using RIL populations. Theor. Appl. Genet. 132:1953-1963.

Thomma, B. P. H. J., Seidl, M. F., Shi-Kunne, X., Cook, D. E., Bolton, M. D., van Kan, J. A. L., and Faino, L. 2016. Mind the gap; seven reasons to close fragmented genome assemblies. Fungal Genet. Biol. 90:24-30.

Walker, B. J., Abeel, T., Shea, T., Priest, M., Abouelliel, A., Sakthikumar, S., Cuomo, C. A., Zeng, Q., Wortman, J., Young, S. K., and Earl, A. M. 2014. Pilon: An integrated tool for comprehensive microbial variant detection and genome assembly improvement. PLoS One 9:e112963.

Wyatt, N. A., Richards, J. K., Brueggeman, R. S., and Friesen, T. L. 2018. Reference assembly and annotation of the Pyrenophora teres f. teres isolate 0-1. G3 (Bethesda) 8:1-8.

Wyatt, N. A., Richards, J. K., Brueggeman, R. S., and Friesen, T. L. 2020. A comparative genomic analysis of the barley pathogen Pyrenophora teres $f$. teres identifies subtelomeric regions as drivers of virulence. Mol. Plant-Microbe Interact. 33:173-188. 